\title{
Combined Open Prostatectomy and Kidney Surgery: Feasibility and I2-Month Outcome
}

\author{
Lukas Rath \\ Friedrich Jokisch \\ Gerald Bastian Schulz \\ Alexander Kretschmer \\ Alexander Buchner (D) \\ Christian G Stief \\ Philipp Weinhold
}

Department of Urology, LudwigMaximilians-University, Munich, Germany

Correspondence: Philipp Weinhold Department of Urology, LudwigMaximilians-University, Marchioninistrasse 15, Munich, 81377,

Germany

Tel +4989-4400-73528

Fax $+49894400-78735$

Email philipp.weinhold@med.uni-

muenchen.de
Purpose: There are only a few case reports and case series that investigated combined laparoscopic or robotic surgery for simultaneous prostate and kidney cancer. In this study, we want to close a gap in existing research to assess the feasibility and oncological outcome of combined open prostatectomy and kidney surgery.

Methods: We retrospectively analyzed patients who underwent a combined open prostatectomy and either a partial or complete nephrectomy from 2013 to 2020. Descriptive statistics were used to assess perioperative parameters and the 12-month functional and oncological outcomes after combined surgery.

Results: We identified 10 patients undergoing combined open surgery. Partial nephrectomy was performed in 4, radical nephrectomy in 6 patients. For prostate cancer, histopathological analysis showed a tumor stage $\geq$ pT2c in all 10 patients. For renal tumors, histopathological analysis showed clear cell renal cell carcinoma in 8 patients and oncocytoma in 2 patients. Operating time was $177 \pm 36$ minutes. Two perioperative complications (Clavien 2a and 3) were observed. Three months postoperatively, the International Index of Erectile Function (IIEF-5) score was 5.6 \pm 5.9 , the ICIQ-SF score was $7.3 \pm 5.6$ and were using $1.9 \pm 2.2$ pads per day. This improved after 12 months postoperatively, as patients had an IIEF- 5 score of $6.33 \pm 6.5$, an ICIQ-SF score of $4.4 \pm 5.7$ and were using pads $0.9 \pm 1.7$ per day.

Conclusion: In this study, we showed that open surgery is a safe and valid approach for combined prostatectomy and renal surgery with acceptable complications and oncological outcomes. The combined open approach could be a good alternative to combined laparoscopic/robotic surgery in this field, especially to treat patients with advanced renal tumors or previous abdominal surgery or radiation.

Keywords: retropubic prostatectomy, kidney surgery, simultaneous prostate and kidney cancer, combined surgery

\section{Introduction}

In the last decades, the incidence of prostate cancer has been steadily increasing due to the widespread practice of prostate-specific antigen (PSA) screening. Additionally, the increase and expansion of routine health examinations and abdominal staging led to an increase in the incidence of renal masses. As a result of this, 1.276.106 new cases of prostate cancer (PCa) and 403.262 new cases of kidney cancer have been reported worldwide in 2018, representing $7.1 \%$ of all cancers in men and $2.2 \%$ in both sexes, respectively. ${ }^{1-3}$ The rate of synchronous prostate and kidney cancer is reported to be $0.83 \%$ in PCa patients and PCa patients have a 6.12 fold increase in the risk of having a synchronous kidney tumor compared to the general population. ${ }^{4,5}$ Abdominal staging work-up for PCa significantly increased 
the detection rate of renal carcinoma compared to the general population with a standardized incidence ratio (SIR) of $18.19 .{ }^{6}$ Usually, the surgical treatment of synchronous prostate and kidney cancer is performed using a two-stage approach with either open or robotic surgery. ${ }^{7,8}$

Combined surgery for simultaneous prostate and kidney cancer has not been established as a standard treatment, but it offers some hypothetical advantages such as reducing the number of hospitalizations, anaesthesia, and postoperative rehabilitations, as well as patient anxiety and cost [9]. There have been several case reports and case series on simultaneous robotic or laparoscopic prostate and kidney surgery, combining robotic prostatectomy with either robotic nephrectomy and unilateral or bilateral partial nephrectomy or laparoscopic and hand assisted nephrectomy or partial nephrectomy with satisfactory results. $^{7-12}$ To the best of our knowledge, no study has investigated the feasibility and safety of a combined open surgical approach for synchronous prostate and kidney cancer. Therefore, the aim of this study is to assess the feasibility, safety and 12-month outcome of a combined open surgical approach to close the gap in existing research.

\section{Materials and Methods}

Between May 2013 and July 2020, a total of 10 patients with synchronous prostate and renal carcinoma were retrospectively identified from a prospective institutional database at LMU University Hospital in Munich.

Written informed consent was obtained from all patients following the Declaration of Helsinki.

For all patients, a multimodal therapy concept was preoperatively discussed in a multidisciplinary tumor board, taking into consideration tumor stages, comorbidities, age, and different approaches of treatment for the individual tumors. Irradiation of the prostate was offered to all patients. With no patient being older than 80 years and tumor infiltration being $\geq 40 \%$ in all prostate biopsies, no patient was considered suitable for active surveillance. Since all patients expressed high urge for curative treatment and were fit for surgery, the decision for a combined surgery was taken. All patients were treated with concurrent radical retropubic prostatectomy (RP) and open renal surgery. The combined surgery was performed exclusively by one experienced surgeon, who has performed over 1000 open RPs and over 1000 partial or complete nephrectomies, to ensure comparability and standardization. Surgical access was through a median laparotomy. The surgical technique of open retropubic RP at our institution has been described before. ${ }^{13,14}$ The surgical approach, ie the order of prostate and kidney surgery, was consistent over all 10 cases with prostatectomy performed first followed by kidney surgery.

Follow-up data were collected from 9 patients up to 12 months after surgery, one patient denied follow-up investigation. Continence status was assessed using the validated ICIQ questionnaire in its short form. ${ }^{15}$ Perioperative complications (90 days) were evaluated using the Clavien-Dindo scale (CDS). ${ }^{16}$ For assessment of patient characteristics, descriptive statistics were used. For comparison of pre- and postoperative serum creatinine levels, Mann-Whitney- $U$ test was used. For comparison of pre-, postoperative and follow up PSA, IIEF and ICIQ, we performed a Kruskal-Wallis-test. Hereby, a p level of $<0.05$ was considered to be statistically significant.

\section{Results}

\section{Patient Characteristics}

Mean age of the patients was $71.3 \pm 6.9$ years. The mean ASA classification of the patients was $1.6 \pm 0.7$. For renal tumor, the preoperative tumor stages according to CT scans were $50 \%$ pT $1 \mathrm{a}, 20 \%$ pT $1 \mathrm{~b}$ and $30 \%$ pT $3 \mathrm{~b}$. The mean preoperative serum creatinine level was $1.16 \pm 0.20 \mathrm{mg} / \mathrm{dl}$. For prostate cancer, the mean preoperative PSA was $15.48 \pm$ $20.33 \mathrm{ng} / \mathrm{mL}$. Preoperative Gleason scores were $\geq 7$ in $80 \%$ of the patients, with Gleason 9 in 4 patients. All patients presented with no sign of metastatic disease (Table 1).

One patient was pretreated by high intensity focused ultrasound (HIFU) for PCa. Two patients had a hernia repaired with mesh insertion. One patient had a previous appendectomy.

\section{Perioperative Parameters and Morbidity (Table I)}

Operating time was $177 \pm 36$ minutes with a blood loss of $690 \pm 529 \mathrm{~mL}$. Partial nephrectomy was performed in 4 patients, radical nephrectomy in 5 patients and radical nephrectomy with cavotomy in 1 patient, respectively.

No intraoperative complications were observed. Postoperatively, we observed a Clavien 2a complication, an intrarenal acute kidney injury, and Clavien 3a complication, for one patient who developed a lymphocele that had to be drained. Furthermore, no patient showed an incisional hernia in follow-up. 
Table I Preoperative and Perioperative Patient Characteristics and Postoperative Prostate and Kidney Cancer Classifications

\begin{tabular}{|c|c|}
\hline Preoperative Characteristics & \\
\hline $\begin{array}{l}\text { Age [years, min, max, mean (SD)] } \\
\text { iPSA [ng/mL, min, max, mean (SD)] } \\
\text { Creatinine }[\mathrm{mg} / \mathrm{dl} \text {, min, max, mean (SD)] }\end{array}$ & $\begin{array}{l}57,81,71(6.9) \\
1.63,71.1,15.48 \\
(20.33) \\
0.9,1.6,1.16(0.20)\end{array}$ \\
\hline $\begin{array}{l}\text { Perioperative Characteristics } \\
\text { Length of Stay [d, min, max, mean (SD)] } \\
\text { Operating Time [minutes, min, max, mean (SD)] } \\
\text { Blood loss [mL, min, max, mean (SD)] } \\
\text { IntraOP Complications } \\
\text { Time to Catheter Removal [d, min, max, mean (SD)] }\end{array}$ & $\begin{array}{l}8,17,10.3(2.8) \\
135,248,177.2(36.6) \\
50,1700,690(529) \\
0 \\
6,14,7.9(2.5)\end{array}$ \\
\hline Prostate cancer & \\
\hline $\begin{array}{l}\text { Tumor Stage } \\
\text { PT2c [N, (\%)] } \\
\text { PT3a [N, (\%)] } \\
\text { PT3b [N, (\%)] }\end{array}$ & $\begin{array}{l}4(40 \%) \\
3(30 \%) \\
3(30 \%)\end{array}$ \\
\hline $\begin{array}{l}\text { Lymph Nodes } \\
\text { NX [N, (\%)] } \\
\text { pNO [N, (\%)] } \\
\text { pNI [N, (\%)] }\end{array}$ & $\begin{array}{l}5(50 \%) \\
3(30 \%) \\
2(20 \%)\end{array}$ \\
\hline $\begin{array}{l}\text { Gleason Score } \\
6[N,(\%)] \\
7 \mathrm{a}[\mathrm{N},(\%)] \\
7 \mathrm{~b}[\mathrm{~N},(\%)] \\
9[\mathrm{~N},(\%)]\end{array}$ & $\begin{array}{l}2(20 \%) \\
3(30 \%) \\
1(10 \%) \\
4(40 \%)\end{array}$ \\
\hline $\begin{array}{l}\text { Positive Surgical Margin (PSM) } \\
\text { RO [N, (\%)] } \\
\text { RI [N, (\%)] }\end{array}$ & $\begin{array}{l}5(50 \%) \\
5(50 \%)\end{array}$ \\
\hline Kidney Cancer & \\
\hline $\begin{array}{l}\text { Tumor Stage } \\
\text { PTla } \\
\text { PTIb } \\
\text { PT3a } \\
\text { Oncocytoma }\end{array}$ & $\begin{array}{l}3(30 \%) \\
2(20 \%) \\
3(30 \%) \\
2(20 \%)\end{array}$ \\
\hline $\begin{array}{l}\text { Lymph Nodes } \\
\text { N0 } \\
\text { NX }\end{array}$ & $\begin{array}{l}3(30 \%) \\
7(70 \%)\end{array}$ \\
\hline $\begin{array}{l}\text { Grading } \\
\text { GI } \\
\text { G2 } \\
\text { G3 }\end{array}$ & $\begin{array}{l}3(30 \%) \\
4(40 \%) \\
3(30 \%)\end{array}$ \\
\hline $\begin{array}{l}\text { Positive Surgical Margin (PSM) } \\
\text { RO }\end{array}$ & $10(100 \%)$ \\
\hline
\end{tabular}

Urinary catheters were removed on the postoperative day $7.9 \pm 2.5$. The average length of hospitalization was $10.3 \pm 2.8$ days.

For $\mathrm{PCa}$, histopathological analysis showed a tumor stage $\geq$ pT2c in all 10 patients with positive lymph nodes in 2 patients. Gleason's scores were 6 in 2, 7a in 3, 7b in 1 and 9 in 4 patients, respectively. Positive surgical margins were observed in 5 specimens. For renal tumors, histopathological analysis showed clear cell renal cell carcinoma stage pT1a in 3 patients, $\mathrm{pT} 1 \mathrm{~b}$ in 2 patients, $\mathrm{pT} 3 \mathrm{a}$ in 3 patients and oncocytoma in 2 patients, showing a postoperative downgrading from $\mathrm{pT} 3 \mathrm{~b}$ to pT3a in 3 cases. Lymph nodes were negative in all patients, and there were no positive surgical margins observed.

\section{Follow-Up Functional Outcome (Table 2)}

After 12 months, six patients were free of biochemical recurrence, two patients received early salvage radiotherapy and one patient received androgen suppression therapy.

Preoperatively the patients presented an International Index of Erectile Function (IIEF-5) of $7.3 \pm 5.4$ and ICIQ of $3.6 \pm 2.2$. Three months postoperatively, patients had an IIEF-5 of $5.6 \pm 5.9$, an ICIQ-SF score of $7.3 \pm 5.6$ and were using $1.9 \pm 2.2$ pads per day. This improved after 12 months postoperatively, as patients had an IIEF-5 score of $6.3 \pm 6.5$, an ICIQ-SF score of $4.4 \pm 5.7$ and were using pads $0.9 \pm 1.7$ per day. Creatinine levels were initially 1.16 $\pm 0.20 \mathrm{mg} / \mathrm{dl}$, significantly rising to $1.77 \pm 0.59(\mathrm{p} \leq 0.01)$ on discharge and declining to $1.57 \pm 0.613$ months and $1.49 \pm 0.6212$ months postoperatively.

\section{Discussion}

To our knowledge, this study presents the first series of combined open radical prostatectomy and renal surgery as treatment for synchronous prostate and renal masses. Due to the low incidence of synchronous PCa and renal masses, and in order to recruit a sufficient number of patients, the different approaches to renal surgery had to be included, ie partial nephrectomy, radical nephrectomy and nephrectomy with cavotomy. Since there were only a few case reports and series published on this subject, these were exclusively considered combined laparoscopic and robotic approaches. We compared our data to these studies as a reference point. 
Table 2 Follow-Up 3 and 12 Months After Surgery

\begin{tabular}{|l|l|l|l|}
\hline Follow-Up & Preoperative & $\mathbf{3}$ Months & I2 Months \\
\hline Creatinine [mg/dl, min, max, mean (SD)] & $1.2,3,1.16(0.20)$ & $1.2,3,1.57(0.6 \mathrm{I})$ & $1.2,3.2,1.49(0.62)$ \\
IIEF [N, min, max, mean (SD)] & $0,22,7.3(5.4)$ & $0,20,5.6(5.9)$ & $0,20,6.3(6.5)$ \\
ICIQ [N, min, max, mean (SD)] & $0,8,3.6(2.2)$ & $0,15,7.3(5.6)$ & $0,15,4.4(5.7)$ \\
Pads/d [N, min, max, mean (SD)] & 0 & $0,6,1.9(2.2)$ & $0,5,0.9(1.7)$ \\
\hline
\end{tabular}

The open retropubic approach has been the gold standard for radical prostatectomy for decades, however with the advent of robotic-assisted laparoscopic surgery, the number of robot-assisted laparoscopic prostatectomies (RALP) has steadily increased, even though no significant differences in patient-reported outcomes and oncological results such as biochemical recurrence rate could be observed between both techniques in prospective and retrospective studies. ${ }^{13,17-19}$ Considering the equality of functional and oncologic outcomes of open prostatectomy and RALP, the laparoscopic robot-assisted surgical approach provides several advantages like a faster postoperative mobilization and a reduced risk for transfusion or surgical site infection. ${ }^{20,21}$ However, with the number of RALPs and the surgical experience in this field steadily increasing, new techniques for intra- and extraperitoneal nerve sparing prostatectomy are emerging, steadily improving the functional postoperative outcomes. ${ }^{22,23}$

In partial nephrectomy and radical nephrectomy, the status of robotic surgery is still under investigation, with a recent review of 16 comparative studies showing no differences in the surgical margin status, the change of glomerular filtration rate and transfusion rate between the two groups. Hereby, robot-assisted partial nephrectomy had a longer operative and warmer ischemia time, but showed slightly lower perioperative blood loss, hospital stay, and perioperative complications. ${ }^{24}$ Due to potential life threatening complications and the extensive surgical field needed for complex operations like nephrectomy with cavotomy, the standard for these operations is still an open approach, as indicated by the lack of comparative studies concerning this subject. ${ }^{25}$ However, some groups have reported cases of combined robotic multivisceral resections like kidney and colorectal surgery for synchronous tumors or kidney and pancreatic surgery for oligometastatic kidney cancer with a synchronous pancreatic metastasis with satisfactory results. ${ }^{26,27}$ Even though the sample size therefore is still small, this indicates that even extended multivisceral resections could be safely performed in a robotic manner.

In our study, the majority of patients had both advanced renal tumor and advanced PCa. One patient was pretreated with HIFU for PCa and two patients previously had abdominal interventions. In our opinion, especially for patients with advanced tumor disease, multiple abdominal preoperations or radiation therapy, a combined open approach is a good option, as it provides a better overview of the operating area, the tactile dimension of the operation and the possibility of faster treatment of intraoperative complications.

Combined surgery for two synchronous urologic cancers offers several advantages for both the patient and the health care system. For the patient, it reduces hospitalization, anesthesia, and postoperative rehabilitation. This may also have an impact on the patient's psychological state. At the same time, the delay of a second oncological operation is avoided. ${ }^{9}$ In addition, both a proven reduction in costs for combined oncological operations and a saving in care capacity is of significant benefit to the health care system. ${ }^{28}$ Despite the low incidence of synchronous prostate and kidney cancer, these factors are nevertheless worth considering. In particular, in times of limited healthcare capacities due to Covid-19 pandemic, combined surgical approaches might be of increased interest.

In this study, it was shown that for all the advantages of combined surgery, the open surgical approach is a safe and feasible alternative to the robotic approach. Due to the lack of retro- or prospective studies in this field, we compared our study mostly to a comprehensive review of the literature on combined laparoscopic or robotic prostate and kidney surgery by Cochetti et al, which summarized 10 different single case studies and series on this subject. ${ }^{9}$ We are aware that a direct comparison of our data with these case series does not yield strong significance but is merely an attempt to classify the previously unpublished combined open approach against the existing data. 
One potential benefit of the open approach might be the shorter operation time. Notably, the average operation time of $177 \pm 36$ min was distinctly shorter in our case series compared to the literature on combined robotic or laparoscopic prostatectomy and kidney surgery, which showed operation times ranging from $240 \mathrm{~min}$ up to 550 min. ${ }^{8,9,29}$ In both approaches, no intraoperative complications were observed. ${ }^{8,9,30}$ On the other hand, the mean estimated blood loss of $690 \pm 529 \mathrm{~mL}$ was higher compared to the laparoscopic approaches with a mean blood loss of $350 \mathrm{~mL}$, which could partly be explained by the pneumoperitoneum in robotic or laparoscopic surgery. ${ }^{9}$ Since no intra- or postoperative blood transfusions were necessary, this difference can be considered significant, but did not impair the patient's outcome.

We observed a Clavien 2a complication, an intrarenal acute kidney injury, which was most likely caused by a change in medication and not surgery related, and Clavien 3a complication, since one patient developed a lymphocele that had to be drained. This is slightly less compared to combined laparoscopic surgery, where a Clavien 3a complication, a bleeding that required angioembolization and Clavien $3 \mathrm{~b}$ complication, an ureteral injury that required ureteroneocystostomy have been observed for the same number of patients. ${ }^{10,30}$

A recent German comparative study of 10.000 prostatectomies performed under similar conditions showed a duration of 7.6 vs 8.0 days for catheter removal for open and robotic prostatectomy, which was very similar to $7.9 \pm 2.7$ days in our study, indicating that synchronous surgery does not necessarily lead to increased rates of anastomotic leakage or prolonged catheter indwelling time. ${ }^{19}$ In addition, a mean hospitalization of 8-9 days was observed in a German multicenter study of partial nephrectomy. ${ }^{31}$ The relatively long average length of stay of $10.30 \pm 2.79$ days is a well-known phenomenon due to the German health care system, which requires a certain length of postoperative hospital stay for full monetary compensation and does not provide for postoperative care facilities. ${ }^{7}$ When comparing the average length of hospital stay for each procedure separately in the German healthcare system, combined surgeries can save estimated 8 days of hospitalization.

For radical prostatectomy, we observed comparable early urinary continence and sexual performance values, as patients used approximately 1 pad per day and had regained $80 \%$ of their initial erectile function 12 months after surgery. ${ }^{19}$ We observed a distinctly higher rate of positive surgical margins (PSM) at 50\% compared to around $13 \%$ in the study by Haese et al or the review by Tang et al. ${ }^{17,19,32}$ This can be explained by the small sample size with a high proportion of advanced tumor stages, since pT2c was the lowest tumor stage and $60 \%$ were pT3a tumors.

The oncologic performance of renal surgery was similar to that reported in the literature, with no PSM, but significantly higher tumor stages observed than with the combined laparoscopic approach. ${ }^{9,24}$ The downgrading from $\mathrm{pT} 3 \mathrm{~b}$ to $\mathrm{pT} 3 \mathrm{a}$ in 3 cases can be explained by differing CT findings and intraoperative results, since in all 3 cases the tumor thrombus was intraoperatively confined to the renal vein. Cavotomy had to be performed in 1 case to ensure no propagation of the thrombus into the Vena cava. We observed a postoperative rise of creatinine from $1.16 \pm 0.2 \mathrm{mg} / \mathrm{dl}$ to $1.77 \pm 0.59 \mathrm{mg} / \mathrm{dl}$, with a decrease to $1.56 \pm 0.60 \mathrm{mg} / \mathrm{dl} 3$ months and to $1.49 \pm$ 0.6212 months postoperatively. This increase may be attributed to 6 procedures consisting of a total nephrectomy and 1 patient with a partial nephrectomy having an intrarenal acute kidney injury. When taking the heterogenicity of procedures performed into account, the alterations of kidney function are within published results. ${ }^{24,31,33}$

When comparing the tumor stages in this study with the laparoscopic or robotic approach, one could identify another potential benefit of the open approach in the ability to treat more advanced tumor stages, especially in renal tumors, since no tumor stage $\geq \mathrm{pT} 3$ was observed in the laparoscopic approach. ${ }^{9}$ Moreover, as mentioned above, the open approach is still the standard for patients that had multiple previous operations or radiation in the field of operation. ${ }^{34,35}$

Limitations of the study include a small patient cohort and retrospective design of the study.

\section{Conclusion}

Our study does not want to show the superiority of combined open surgery versus laparoscopic or robotic surgery, but to close a gap in existing research. Our case series demonstrates that combined open prostatectomy and renal surgery is a safe and valid approach in carefully selected patients with acceptable complications and oncological outcomes. Advantages of combined open surgical procedures could include the ability to treat patients with advanced renal tumors or previous abdominal surgery or radiation without clinically significant blood loss. However, larger clinical trials are needed to further 
evaluate the best treatment options for synchronous prostate and kidney cancer.

\section{Ethics Approval and Consent to Participate}

All patients gave their informed consent and the study protocol was approved by the Institutional Review Board (IRB) of the Ludwig-Maximilians-University, Munich, Germany. Institution Review Board (IRB) number: 201022. The study was performed in accordance with the Declaration of Helsinki.

\section{Funding}

The authors did not receive any funding for this study.

\section{Disclosure}

The authors declare that they have no competing interests.

\section{References}

1. Barocas DA, Rabbani F, Scherr DS, Vaughan ED Jr. A population-based study of renal cell carcinoma and prostate cancer in the same patients. BJU Int. 2006;97(1):33-36. doi:10.1111/j.1464410X.2005.05880.x

2. Maruthappu M, Barnes I, Sayeed S, Ali R. Incidence of prostate and urological cancers in England by ethnic group, 2001-2007: a descriptive study. BMC Cancer. 2015;15:753. doi:10.1186/s12885015-1771-2

3. Bray F, Ferlay J, Soerjomataram I, Siegel RL, Torre LA, Jemal A. Global cancer statistics 2018: GLOBOCAN estimates of incidence and mortality worldwide for 36 cancers in 185 countries. $C A$ Cancer J Clin. 2018;68(6):394-424. doi:10.3322/caac.21492

4. Murray KS, Zabor EC, Spaliviero M, et al. Second primary malignancies in renal cortical neoplasms: an updated evaluation from a single institution. World J Urol. 2016;34(12):1667-1672. doi:10.1007/s00345-016-1832-4

5. Looney AT, Nason GJ, McGuire BB, et al. Incidentalology: a developing urological sub-specialty. Surgeon. 2014;12 (6):301-306. doi:10.1016/j.surge.2013.08.004

6. Ozsoy O, Fioretta G, Ares C, Miralbell R. Incidental detection of synchronous primary tumours during staging workup for prostate cancer. Swiss Med Wkly. 2010;140(15-16):233-236.

7. Patel MN, Eun D, Menon M, Rogers CG. Combined robotic-assisted laparoscopic partial nephrectomy and radical prostatectomy. JSLS. 2009;13(2):229-232.

8. Jung JH, Arkoncel FR, Lee JW, et al. Initial clinical experience of simultaneous robot-assisted bilateral partial nephrectomy and radical prostatectomy. Yonsei Med J. 2012;53(1):236-239. doi:10.3349/ ymj.2012.53.1.236

9. Cochetti G, Cocca D, Maddonni S, et al. Combined robotic surgery for double renal masses and prostate cancer: myth or reality? Medicina. 2020;56(6). doi:10.3390/medicina56060318

10. Jung JH, Kim HW, Oh CK, et al. Simultaneous robot-assisted laparoendoscopic single-site partial nephrectomy and standard radical prostatectomy. Yonsei Med J. 2014;55(2):535-538. doi:10.3349/ ymj.2014.55.2.535

11. Finley DS, Melamud O, Ornstein DK. Combined robot-assisted laparoscopic nephroureterectomy and radical prostatectomy. J Endourol. 2007;21(4):411-414. doi:10.1089/end.2007.0013
12. Oda J, Landman J, Bhayani S, Figenshau RS. Concomitant laparoscopic hand-assisted radical nephrectomy and open radical prostatectomy using a single lower midline incision. Urology. 2000;56 (6):1056. doi:10.1016/s0090-4295(00)00809-8

13. Kretschmer A, Bischoff R, Chaloupka M, et al. Health-related quality of life after open and robot-assisted radical prostatectomy in low- and intermediate-risk prostate cancer patients: a propensity score-matched analysis. World J Urol. 2020;38(12):3075-3083. doi:10.1007/s00345020-03144-9

14. Kretschmer A, Mandel P, Buchner A, Stief CG, Tilki D. Surgical learning curve for open radical prostatectomy: is there an end to the learning curve? World J Urol. 2015;33(11):1721-1727. doi:10.1007/ s00345-015-1540-5

15. Avery K, Donovan J, Peters TJ, Shaw C, Gotoh M, Abrams P. ICIQ: a brief and robust measure for evaluating the symptoms and impact of urinary incontinence. Neurourol Urodyn. 2004;23(4):322-330. doi:10.1002/nau.20041

16. Dindo D, Demartines N, Clavien PA. Classification of surgical complications: a new proposal with evaluation in a cohort of 6336 patients and results of a survey. Ann Surg. 2004;240(2):205-213. doi:10.1097/01.sla.0000133083.54934.ae

17. Basiri A, de la Rosette JJ, Tabatabaei S, Woo HH, Laguna MP, Shemshaki H. Comparison of retropubic, laparoscopic and robotic radical prostatectomy: who is the winner? World J Urol. 2018;36 (4):609-621. doi:10.1007/s00345-018-2174-1

18. Coughlin GD, Yaxley JW, Chambers SK, et al. Robot-assisted laparoscopic prostatectomy versus open radical retropubic prostatectomy: 24-month outcomes from a randomised controlled study. Lancet Oncol. 2018;19(8):1051-1060. doi:10.1016/S1470-2045(18)30357-7

19. Haese A, Knipper S, Isbarn H, et al. A comparative study of robot-assisted and open radical prostatectomy in 10790 men treated by highly trained surgeons for both procedures. BJU Int. 2019;123 (6):1031-1040. doi:10.1111/bju.14760

20. de Vermandois JAR, Cochetti G, Zingaro MD, et al. Evaluation of surgical site infection in mini-invasive urological surgery. Open Med. 2019;14:711-718. doi:10.1515/med-2019-0081

21. Mearini E, Cirocchi R, Cochetti G. Robot-assisted surgery in urology: the show must go on. Editorial. Appl Sci. 2019;9(5):844. doi:10.3390/app9050844

22. Cochetti G, Boni A, Barillaro F, Pohja S, Cirocchi R, Mearini E. Full neurovascular sparing extraperitoneal robotic radical prostatectomy: our experience with PERUSIA technique. J Endourol. 2017;31 (1):32-37. doi:10.1089/end.2016.0477

23. Cochetti G, Del zingaro M, Ciarletti S, et al. New evolution of robotic radical prostatectomy: a single center experience with PERUSIA technique. Appl Sci. 2021;11(4):1513. doi:10.3390/app11041513

24. Shen Z, Xie L, Xie W, et al. The comparison of perioperative outcomes of robot-assisted and open partial nephrectomy: a systematic review and meta-analysis. World J Surg Oncol. 2016;14(1):220. doi:10.1186/s12957-016-0971-9

25. Shi T, Huang Q, Liu K, et al. Robot-assisted cavectomy versus thrombectomy for level II inferior vena cava thrombus: decision-making scheme and multi-institutional analysis. Eur Urol. 2020;78(4):592-602. doi:10.1016/j.eururo.2020.03.020

26. Cochetti G, Tiezzi A, Spizzirri A, et al. Simultaneous totally robotic rectal resection and partial nephrectomy: case report and review of literature. World J Surg Oncol. 2020;18(1):86. doi:10.1186/s12957020-01864-1

27. Boni A, Cochetti G, Ascani S, et al. Robotic treatment of oligometastatic kidney tumor with synchronous pancreatic metastasis: case report and review of the literature. BMC Surg. 2018;18(1):40. doi:10.1186/s12893-018-0371-x

28. Lavery HJ, Patel S, Palese M, Kasabian NG, Gainsburg DM, Samadi DB. Combined robotic radical prostatectomy and robotic radical nephrectomy. JSLS. 2010;14(4):603-607. doi:10.4293/ $108680810 X 12924466008763$ 
29. Raheem AA, Santok GD, Kim DK, et al. Simultaneous Retzius-sparing robot-assisted radical prostatectomy and partial nephrectomy. Investig Clin Urol. 2016;57(2):146-149. doi:10.4111/ icu.2016.57.2.146

30. Boncher N, Vricella G, Greene G, Madi R. Concurrent robotic renal and prostatic surgery: initial case series and safety data of a new surgical technique. $J$ Endourol. 2010;24(10):1625-1629. doi:10.10 89/end.2010.0151

31. Harke NN, Darr C, Radtke JP, et al. Retroperitoneal versus transperitoneal robotic partial nephrectomy: a multicenter matched-pair analysis. Eur Urol Focus. 2020. doi:10.1016/j.euf.2020.08.012

32. Tang K, Jiang K, Chen $\mathrm{H}$, Chen Z, Xu H, Ye Z. Robotic vs. Retropubic radical prostatectomy in prostate cancer: a systematic review and an meta-analysis update. Oncotarget. 2017;8 (19):32237-32257. doi:10.18632/oncotarget.13332
33. Chebbi A, Benoit T, Giwerc A, et al. [Partial nephrectomy vs. radical nephrectomy for tumor $>7 \mathrm{~cm}$ ] Resultats de la nephrectomie partielle pour les tumeurs de plus de $7 \mathrm{~cm}$ : comparaison avec la nephrectomie elargie. Prog Urol. 2017;27(2):80-86. doi:10.1016/j.purol.201 6.12 .002

34. Cartapatti M, Machado RD, Muller RL, et al. Synchronous abdominal tumors: is combined laparoscopic surgery in a single approach a safe option? Int Braz J Urol. 2018;44(3):483-490. doi:10.1590/ S1677-5538.IBJU.2017.0429

35. Pisipati S, Bach C, Daneshwar D, Rowe EW, Koupparis AJ. Concurrent upper and lower urinary tract robotic surgery: a case series. Can Urol Assoc J. 2014;8(11-12):E853-8. doi:10.5489/ cuaj. 1836

\section{Publish your work in this journal}

Research and Reports in Urology is an international, peer-reviewed, open access journal publishing original research, reports, editorials, reviews and commentaries on all aspects of adult and pediatric urology in the clinic and laboratory including the following topics Pathology, pathophysiology of urological disease; Investigation and treatment of urological disease; Pharmacology of drugs used for the treatment of urological disease. The manuscript management system is completely online and includes a very quick and fair peer-review system, which is all easy to use. Visit http://www.dovepress.com/ testimonials.php to read real quotes from published authors. 